\title{
A case-control study of glycemic index, glycemic load and dietary fiber intake and risk of adenocarcinomas and squamous cell carcinomas of the esophagus: the Australian Cancer Study
}

Petra H Lahmann ${ }^{1,2^{*}}$, Torukiri I Ibiebele ${ }^{1}$, Penelope M Webb ${ }^{1}$, Christina M Nagle ${ }^{1}$, David C Whiteman ${ }^{1}$ and for the Australian Cancer Study

\begin{abstract}
Background: Glycemic index (Gl) and glycemic load (GL) have been investigated as etiologic factors for some cancers, but epidemiological data on possible associations between dietary carbohydrate intake and esophageal cancer are scant. This study examined the association between $\mathrm{Gl}, \mathrm{GL}$, and other dietary carbohydrate components and risk of adenocarcinomas and squamous cell carcinoma of the esophagus accounting for established risk factors.

Methods: We analyzed data from a population-based Australian case-control study (2002-05) comprising 299 adenocarcinoma (EAC), 337 gastro-esophageal junction adenocarcinoma (EGJAC), 245 squamous cell carcinoma (ESCC), and 1507 controls sampled from a population registry. Dietary information was obtained using a 135-item food frequency questionnaire (FFQ); GI and GL were derived from an Australian GI database. Multivariable logistic regression models were used to derive odds ratios (ORs).
\end{abstract}

Results: All three case groups tended to have a lower intake of fiber, and significantly higher intake of fat, total energy, and alcohol (ESCC only) compared to controls. GI was unrelated to all histological types. Higher GL was not associated with risk of EAC and EGJAC, but was inversely associated with risk of ESCC (adjusted model, ptrend $=0.006$ ), specifically among men where we observed a 58\% reduced risk of ESCC in the highest versus the lowest quartile. Increased intake of total carbohydrates and starch was related to similarly large risk reductions of ESCC. Fiber intake was strongly and inversely associated with risk of EAC, EGJAC and ESCC (all $p_{\text {trend }} \leq 0.001$ ), indicating risk reductions of 28\%-37\% per $10 \mathrm{~g} /$ day.

Conclusions: This study suggests a reduced risk of esophageal SCC with higher GL level particularly in men, but provides no evidence for the role of Gl in the development of esophageal cancer. In addition, increased fiber intake appears to be associated with lower risk of all histological types of esophageal cancer.

Keywords: Esophageal cancer, Glycemic index/load, Fiber intake

\footnotetext{
* Correspondence: plahmann@gmx.de

'Population Health Department, QIMR Berghofer Medical Research Institute, 300 Herston Road, Herston, Brisbane, QLD 4006, Australia

${ }^{2}$ School of Population Health, University of Queensland, Herston, QLD 4006, Australia
} Commons Attribution License (http://creativecommons.org/licenses/by/4.0), which permits unrestricted use, distribution, and reproduction in any medium, provided the original work is properly credited. The Creative Commons Public Domain Dedication waiver (http://creativecommons.org/publicdomain/zero/1.0/) applies to the data made available in this article, unless otherwise stated. 


\section{Background}

Esophageal cancer is the eighth most common cancer worldwide, and the sixth most common cause of death from cancer [1]. The common histologic types of esophageal cancer, adenocarcinoma (EAC), gastro-esophageal junction adenocarcinoma (EGJAC) and squamous cell carcinoma (ESCC) represent different disease entities with distinct risk factor patterns [2]. While smoking, alcohol consumption and some dietary factors are the predominant risk factors for SCC, male sex, age, race, obesity and obesity-related factors are the main risk factors for EAC and EGJAC. Factors related to glucose metabolism and energy balance have been implicated in the development of a number of cancers [3,4] and glycemic index (GI) and glycemic load (GL), both reflecting the metabolic effects of dietary carbohydrates, have been examined as possible etiologic factors [5-7]. The glycemic index ranks carbohydrate foods according to a standard food (usually glucose or white bread) based on their postprandial blood glucose response and blood insulin levels [5,8-10]. The glycemic load combines the glycemic index value and the quantity of carbohydrate ( $\mathrm{g}$ ) to quantify the overall estimated glycemic effect of standard portion sizes of foods [8,11]. Persistently high GI and GL intakes may lead to chronic elevations in blood glucose concentrations, while hyperglycemia, type 2 diabetes, and hyperinsulinemia have been implicated as potential risk factors for some cancers, including cancers of the digestive tract [12-14]. Further, a high-GI diet may increase cancer risk by modulating the insulin-like-growth factor (IGF) axis [15,16]. Insulin resistance and altered levels of IGF compounds have been suggested to influence the healing of esophageal mucosal injury and esophageal cell apoptosis [12].

Results from recent meta-analyses of observational studies $[6,13]$ on the association between GI or GL and cancer risk, however, are mixed. Pooled risk estimates from case-control and cohort studies combined indicate a positive association between GI or GL and colorectal cancer risk, but not in cohort studies alone, and notably, no association with pancreatic or other digestive tract cancers.

Epidemiological data on dietary carbohydrate intake and esophageal cancer are scant $[13,17]$. Ecological data suggest a strong correlation between carbohydrate consumption and the incidence of EAC [7]. Over the past decade two case-control studies observed slightly increased, but statistically non-significant risks for EAC [18] and ESCC [19] with higher level of GI or GL. A single prospective study [20] found that higher GI, but not GL, was significantly associated with elevated risk of esophageal cancer (EAC and ESCC cases combined) among men only. A succeeding analysis of the same cohort indicated an increased risk of esophageal adenocarcinoma with high intake of added sugars in men [21].
None of these investigations examined different histologic subtypes simultaneously to reveal any potential associations arising from their different etiologies. We therefore used data from a large population-based casecontrol study to examine the association between GI, GL, and other dietary carbohydrate components (total carbohydrates, starch, total sugars, fiber) and risk of EAC, EGJAC, and ESCC accounting for established risk factors and exploring potential effect modifiers.

\section{Patients and methods}

\section{Study population}

We used data from an Australian population-based case-control study of esophageal cancer (Australian Cancer Study, ACS) and restricted the current analysis to the group of patients who had histologically confirmed primary, invasive EAC, EGJAC or ESCC and a population-based control group. Tumors were categorized as 'esophageal' and 'esophagogastric junction' tumors according to the WHO classification [22]. Full details on the study design and recruitment have been published previously [23]. In brief, the patients (cases) were adults ages 18 to 79 years who had primary invasive carcinoma of the esophagus (ICD-10 C15) diagnosed between July 1, 2002 (July 1, 2001 in Queensland) and June 30, 2005 in the mainland states of Australia. Patients were recruited either through major treatment centers or through state-based cancer registries. Of 1,577 patients who were invited to participate in the study, 1,102 returned a completed questionnaire $(70 \%$ of all those invited; $35 \%$ of all eligible patients living or deceased). Seven of these patients were deemed ineligible on pathology review and were excluded. Potential controls were selected randomly from the Australian Electoral Roll (enrolment is compulsory) within 5 -year age groups and state of residence to match the distribution of the case series. Women were intentionally over sampled in the control group at all ages to accommodate their simultaneous enrolment in a parallel casecontrol study of ovarian cancer [24]. Of 3,042 eligible controls who were contacted, 1,580 (51\%) returned completed questionnaires. For the present analyses, we excluded 152 cases and 47 control participants who did not return the food frequency questionnaire (FFQ), 35 cases and 5 controls with more than 10\% of FFQ items missing, and 27 cases and 21 controls whose estimated caloric intake was extreme $(<700$ or $>4000 \mathrm{kcal})$, leaving a final sample of 1,507 controls and 881 cases. The cases consisted of 299 (M/F 271/28) EAC cases, 337 (M/F 289/48) EGJAC cases, and 245 (M/F147/98) ESCC cases for analysis. The study was approved by the human research ethics committee of the QIMR Berghofer Institute of Medical Research and all participating institutions (Additional file 1: Table S1). All study participants provided informed written consent to take part. 


\section{Dietary assessment}

Dietary information was obtained using a 135-item semiquantitative FFQ based on the instrument developed by Willett et al. [25], but modified for use in Australia [26,27] and validated against 12-days weighed food records $[28,29]$. Assessment of our FFQ relative to the food records showed moderate correlation coefficients ( $\mathrm{r}$ ) of 0.45 , $0.42,0.53$, and 0.39 for total carbohydrates, starch, total sugars, and fiber respectively for all participants [28]. Cases were asked to report their usual frequency of consumption in the year before their diagnosis or, if their diet had changed in the last 6-12 months, their usual diet. Controls were asked to report how often they consumed a specified amount of each food item in the previous year. Daily intake of energy ( $\mathrm{kcal} / \mathrm{d})$, macronutrients and carbohydrate components (g/d) was estimated using Australian food composition tables as contained in NUTTAB2006 [30]. The sugar variable used was total sugars (g/d) which includes dietary mono- and disaccharides (fructose, glucose, sucrose, maltose, lactose, galactose) [30].

To calculate GL and GI, we used an Australian GI database (FoodWorks: Professional Edition, 2007) that compiled GI values based on carbohydrate-containing food items to reflect their blood glucose response. Data not available in FoodWorks were supplemented with GI values obtained from tables compiled by Atkinson and coworkers [31]. We calculated total dietary GL of a food item by multiplying the amount of carbohydrate contained in a specified serving size of the food by the quantity of that food item consumed per day and its corresponding GI value (using glucose as the reference food). We then summed the values for all carbohydrate containing foods reported on the FFQ to estimate total GL [31,32]. The overall GI was calculated by dividing the total dietary GL by the total available carbohydrate intake.

\section{Covariates}

Study participants provided detailed health and lifestyle information via a self-administered questionnaire [24]. Participants were asked to report their height and weight one year before diagnosis for cases and one year before study recruitment for controls. BMI (last year) was calculated as weight divided by height $\left(\mathrm{kg} / \mathrm{m}^{2}\right)$ and used as a predefined categorical variable according to commonly used definitions of overweight and obesity [33]. Number of pack-years of tobacco exposure was derived by dividing the number of cigarettes smoked daily by 20 and multiplying by the total number of years smoked (never smoked, <15, 15-<30, $\geq 30$ pack-years). Other known risk factors included in the analysis were age (y, continuous), sex (male/female), education (highschool or less, trade/diploma, university), lifetime alcohol consumption (abstainer, <0-6, 7-20, >21 standard drinks of $10 \mathrm{~g}$ alcohol units/week), recreational physical activity index (low, moderate, high level based on frequency and intensity of activity per week) [34], use of aspirin or other nonsteroidal anti-inflammatory drugs (NSAIDs) in the last 5 years (never user, occasionally, <weekly, zweekly), symptoms of gastro-esophageal reflux 10 years before diagnosis (never, occasionally, <weekly, zweekly), presence of diabetes type 2 (no/yes, self-reported), and the following dietary factors: fruit intake $(\mathrm{g} / \mathrm{d})$, red and processed meat $(\mathrm{g} / \mathrm{d})$, and energy intake $(\mathrm{kcal} / \mathrm{d})$.

\section{Statistical analysis}

We calculated the odds ratio (OR) and 95\% confidence interval (95\% CI) associated with each dietary exposure using multivariable unconditional logistic regression analysis. We combined the sexes for analysis due to small numbers of female cases, especially for esophageal adenocarcinomas. All dietary variables were adjusted for total energy intake using the nutrient residual method as described by Willett [25] and log-transformed prior to calculation of the residuals. Participants were categorized into sex-specific quartiles based on the distribution of GI, GL and other dietary carbohydrates (total carbohydrates, starch, total sugars, fiber) among the male or female controls, respectively. The first model was minimally adjusted for age and sex (data not shown). The final multivariable model was additionally adjusted for other established risk factors and other potential confounders relevant to each subtype of esophageal cancer: education, BMI last year, smoking (pack-years), lifetime mean alcohol consumption, physical activity, NSAIDs, acid reflux symptoms in last 10 years (not for ESCC), presence of diabetes (not for ESCC), and selected dietary factors. To test for linear trend across categories, the median value in each quartile was modeled as a continuous variable. Risk estimates from multivariable adjusted models were slightly attenuated, but not materially different from age and sex adjusted models; therefore results from multivariable adjusted models are presented only.

We conducted subgroup analyses to examine whether the associations between GI, GL and dietary carbohydrates were modified by sex, BMI $(<25$ and $\geq 25)$, smoking status (ever/never), or current alcohol consumption $(</>$ sexspecific median $\mathrm{g} / \mathrm{d}$ ), red meat and saturated fat intake $(</>$ sex-specific median g/d), diabetes type 2 (yes/no, EAC and EGJAC only), acid reflux symptoms (ever/never, EAC and EGJAC only). The statistical significance of any observed stratum differences was assessed by including a cross-product term in regression models. We present sexstratified analysis for ESCC only in supplementary material. Further, we conducted sensitivity analysis, using a) a combined smoking variable derived from current smoking status and pack-years, b) explored various energy adjustments, c) omitted BMI from multivariable analysis for EAC. All analyses were conducted using the SAS statistical 
Table 1 Non-dietary and dietary characteristics of study participants, $N=2,388$

\begin{tabular}{|c|c|c|c|c|c|c|c|}
\hline \multirow[t]{2}{*}{ Characteristics } & \multirow{2}{*}{$\begin{array}{l}\text { Controls } \\
N=1507\end{array}$} & \multirow{2}{*}{$\begin{array}{l}\text { EAC } \\
N=299\end{array}$} & \multirow[t]{2}{*}{$P$ value $^{a}$} & \multirow{2}{*}{$\begin{array}{l}\text { EGJAC } \\
N=337\end{array}$} & \multirow[t]{2}{*}{$P$ value $^{a}$} & ESCC & \multirow[t]{2}{*}{$P$ value } \\
\hline & & & & & & $N=245$ & \\
\hline \multicolumn{8}{|l|}{ Non-dietary factors } \\
\hline Age $(y$, mean, SD) & $61(12)$ & $64(10)$ & $<0.0001$ & $63(10)$ & $<0.0001$ & $65(9)$ & $<0.0001$ \\
\hline \multicolumn{8}{|l|}{ Sex (\%) } \\
\hline Female & 34 & 9 & $<0.0001$ & 14 & $<0.0001$ & 40 & 0.06 \\
\hline Male & 66 & 91 & & 86 & & 60 & \\
\hline \multicolumn{8}{|l|}{ Educational level (\%) } \\
\hline Highschool or less & 40.9 & 46.5 & 0.0002 & 37.7 & 0.01 & 57.1 & $<0.0001$ \\
\hline Trade/diploma & 43.6 & 47.2 & & 51.6 & & 34.3 & \\
\hline University degree & 15.5 & 6.3 & & 10.7 & & 8.6 & \\
\hline Body mass index $\left(\mathrm{kg} / \mathrm{m}^{2}, \%\right)$ & & & & & & s & \\
\hline$<25$ & 36.2 & 20.5 & $<0.0001$ & 27.4 & $<0.0001$ & 55.5 & $<0.0001$ \\
\hline $25-<30$ & 43.3 & 42.7 & & 39.2 & & 30.4 & \\
\hline$\geq 30$ & 20.5 & 36.8 & & 33.4 & & 14.1 & \\
\hline \multicolumn{8}{|l|}{ Physical activity index (\%) } \\
\hline Low & 19.3 & 23.8 & 0.33 & 21.7 & 0.76 & 29.5 & 0.0003 \\
\hline Moderate & 41.0 & 36.6 & & 37.7 & & 30.7 & \\
\hline High & 39.7 & 39.6 & & 40.6 & & 39.8 & \\
\hline \multicolumn{8}{|l|}{$\begin{array}{l}\text { Cumulative smoking history } \\
\text { (pack-years, \%) }\end{array}$} \\
\hline Never smoked & 44.7 & 25.1 & $<0.0001$ & 24.3 & $<0.0001$ & 23.1 & $<0.0001$ \\
\hline$<15$ & 25.2 & 20.1 & & 19.9 & & 19.7 & \\
\hline $15-29.9$ & 13.3 & 19.1 & & 22.3 & & 20.2 & \\
\hline$\geq 30$ & 16.8 & 35.7 & & 33.5 & & 37.0 & \\
\hline \multicolumn{8}{|l|}{$\begin{array}{l}\text { Lifetime alcohol consumption } \\
\text { (10 g alcohol units/wk) (\%) }\end{array}$} \\
\hline Abstainer & 10.7 & 6.4 & $<0.0001$ & 9.2 & 0.0004 & 12.7 & $<0.0001$ \\
\hline$>0-6$ drinks/wk & 38.1 & 27.8 & & 29.7 & & 26.6 & \\
\hline 7-20 drinks/wk & 31.9 & 36.6 & & 33.5 & & 20.9 & \\
\hline$\geq 21$ drinks/wk & 19.3 & 29.2 & & 27.6 & & 39.8 & \\
\hline \multicolumn{8}{|c|}{ Reflux symptoms 10 years ago (\%) } \\
\hline Never & 43.1 & 21.5 & $<0.0001$ & 29.7 & $<0.0001$ & 46.0 & $<0.0001$ \\
\hline Occasionally & 30.5 & 13.5 & & 16.1 & & 13.0 & \\
\hline$<$ Weekly & 14.5 & 22.6 & & 22.6 & & 13.0 & \\
\hline$\geq$ Weekly & 11.9 & 42.4 & & 31.6 & & 28.0 & \\
\hline \multicolumn{8}{|l|}{ NSAID use (\%) } \\
\hline Never user & 43.7 & 46.3 & 0.24 & 47.6 & 0.62 & 51.4 & 0.07 \\
\hline Occasionally & 31.4 & 26.0 & & 28.7 & & 27.4 & \\
\hline$<$ Weekly & 9.0 & 8.8 & & 9.0 & & 7.5 & \\
\hline$\geq$ Weekly & 15.9 & 18.9 & & 14.7 & & 13.7 & \\
\hline \multicolumn{8}{|l|}{ Presence of Diabetes (\%) } \\
\hline No & 93.0 & 87.6 & 0.002 & 88.2 & 0.02 & 95.8 & 0.09 \\
\hline Yes & 7.0 & 12.4 & & 11.2 & & 4.2 & \\
\hline
\end{tabular}


Table 1 Non-dietary and dietary characteristics of study participants, $\mathbf{N}=\mathbf{2 , 3 8 8}$ (Continued)

\begin{tabular}{|c|c|c|c|c|c|c|c|}
\hline \\
\hline \multicolumn{8}{|l|}{$\begin{array}{l}\text { Dietary factors(Mean, SD) } \\
\text { Glycemic Index }\end{array}$} \\
\hline Glycemic load ${ }^{c}$ & $120(23)$ & $119(22)$ & 0.41 & $118(22)$ & 0.18 & $115(25)$ & 0.002 \\
\hline Total carbohydrates $(\mathrm{g})^{c}$ & $234(34)$ & $231(34)$ & 0.14 & $229(31)$ & 0.01 & $221(37)$ & $<0.0001$ \\
\hline Total sugars $(g)^{c}$ & $128(35)$ & $127(33)$ & 0.49 & $124(33)$ & 0.05 & $117(38)$ & $<0.0001$ \\
\hline Starch $(g)^{c}$ & $101(24)$ & $98(25)$ & 0.04 & $99(24)$ & 0.28 & $94(27)$ & 0.001 \\
\hline Dietary Fiber $(\mathrm{g})^{c}$ & $31(9)$ & $28(8)$ & $<0.0001$ & $27(8)$ & $<0.0001$ & $28(9)$ & $<0.0001$ \\
\hline Protein (g) & $93(15)$ & $91(14)$ & 0.25 & $92(15)$ & 0.29 & $89(17)$ & 0.003 \\
\hline Fat (g) & $71(12)$ & $73(12)$ & 0.04 & $74(11)$ & 0.001 & $73(13)$ & 0.03 \\
\hline Saturated fat (g) & $27(7)$ & $29(7)$ & $<0.0001$ & $30(7)$ & $<0.0001$ & $29(7)$ & 0.0005 \\
\hline MUFA (g) & $25(6)$ & $25(5)$ & 0.65 & $26(5)$ & 0.02 & $25(6)$ & 0.67 \\
\hline PUFA (g) & $11(3)$ & $10(3)$ & 0.002 & $11(3)$ & 0.48 & $11(3)$ & 0.80 \\
\hline Alcohol consumption $(\mathrm{g})^{d}$ & $13(16)$ & $14(16)$ & 0.20 & $13(17)$ & 0.78 & $21(24)$ & $<0.0001$ \\
\hline Total Energy (kcal) & $2215(644)$ & 2395 (729) & $<0.0001$ & $2396(700)$ & $<0.0001$ & $2270(795)$ & $<0.0001$ \\
\hline$\%$ energy from $\mathrm{CHO}$ & $45(7)$ & $45(7)$ & 0.23 & $45(6)$ & 0.03 & $43(7)$ & $<0.0001$ \\
\hline$\%$ energy from protein & $18(3)$ & $18(7)$ & 0.06 & $18(3)$ & 0.08 & $17(3)$ & 0.003 \\
\hline$\%$ energy from fat & $30(5)$ & $31(5)$ & 0.02 & $31(5)$ & $<0.0001$ & $31(5)$ & 0.03 \\
\hline
\end{tabular}

${ }_{\mathrm{a}}^{\mathrm{p}}$-level chi-square test for categorical variables or chi-square test for trend, and $t$-test for continuous variables.

${ }^{b}$ dietary variables adjusted for energy intake (nutrient residual method), except for Gl.

${ }^{c}$ Median values for dietary exposure variables by sex (male/female controls): Gl 52/50, GL 121/116, total carbohydrates $234 / 236 \mathrm{~g} / \mathrm{d}$, total sugars $123 / 132 \mathrm{~g} / \mathrm{d}$,

starch $100 / 100 \mathrm{~g} / \mathrm{d}$, dietary fiber $29 / 32 \mathrm{~g} / \mathrm{d}$.

${ }^{d}$ current alcohol consumption (FFQ).

software, version 9.1 (SAS Institute, Cary, NC), and statistical tests were 2 -sided with $P$-values $<0.05$ considered statistically significant.

\section{Results}

Study participants characteristics by subtype of esophageal cancer are provided in Table 1 . Overall, cases were predominantly male, with the highest proportion of women (40\%) among ESCC cases. Compared to controls, all 3 groups of cases tended to be older on average, were less likely to have a university degree, more likely to be heavy smokers ( $\geq 30$ pack years) and heavy drinkers ( $\geq 21$ drinks/ week, lifetime) and to have a low physical activity level (ESCC only). As expected, the proportion of obese individuals among EAC (37\%) and EGJAC (33\%) cases, but not ESCC (14\%) cases, was substantially higher than among controls (21\%). Likewise, diabetes was more common among EAC and EGJAC cases (11-12\%) compared to their control counterparts (7\%). Aspirin/NSAID use did not differ significantly by case status. With regard to dietary factors, all three groups of cases tended to have a lower intake of fiber and protein (ESCC only), and higher intake of total energy, total fat (g/day or \% energy), saturated fat, and for ESCC cases only, higher current alcohol consumption (g/day) as compared to controls. Among all study participants, vegetables (41\%), fruit (28\%), and grains $(23 \%)$ were the main food sources of dietary fiber (\% of total intake); grains (56\%), vegetables (28\%), and sweet snacks (10\%) of starch; and fruit (36\%), sweet snacks (23\%), dairy products (20\%), and soft drinks (9\%) of total sugars.

Tables 2 and 3 present adjusted ORs for each subtype of esophageal cancer according to intakes of GI, GL, carbohydrate components and fiber for men and women combined. GI and GL were not associated with risk of EAC or EGJAC (Table 2), whereas higher GL was associated significantly and inversely with risk of ESCC (Table 3 ) in the fully adjusted model $\left(\mathrm{p}_{\text {trend }}=0.006\right)$. We observed a $48 \%$ reduced risk of ESCC in the highest quartile compared with the lowest (reference) quartile. GI was unrelated to risk of ESCC. In sensitivity analyses (not shown), we additionally adjusted for fiber intake in the multivariable models. Risk estimates were not materially different for any case group. Further, to test for confounding or mediating effects of diabetes or BMI, we conducted sensitivity analyses especially for adenocarcinomas (not shown). We excluded individuals with diabetes in each dietary exposure multivariable model, and separately, for total sugars intake only, we omitted BMI from the multivariable model. ORs were not significantly changed in any of these analyses.

Total carbohydrate intake or selected carbohydrate components were not related to risk of EAC and EGJAC (Table 2). In contrast, mean intake of total carbohydrate and starch was associated with similarly large risk reductions (54\%) of ESCC (Table 3), when comparing highest 
Table 2 Odds ratios and $95 \%$ confidence intervals for esophageal adenocarcinomas and gastro-esophageal junction adenocarcinomas according to glycemic index, glycemic load, and dietary carbohydrate intakes, Australia 2002-2005

\begin{tabular}{|c|c|c|c|c|c|}
\hline & \multirow{3}{*}{$\begin{array}{l}\text { Controls } \\
\mathrm{N}=1490\end{array}$} & \multirow{2}{*}{\multicolumn{2}{|c|}{$\begin{array}{c}\text { EAC } \\
\text { Multivariable model }^{\mathrm{a}}\end{array}$}} & \multirow{2}{*}{\multicolumn{2}{|c|}{$\begin{array}{c}\text { EGJAC } \\
\text { Multivariable model }^{\mathrm{a}}\end{array}$}} \\
\hline & & & & & \\
\hline & & $\mathrm{N}=\mathbf{2 8 8}$ & OR, $(95 \% \mathrm{Cl})$ & $\mathrm{N}=318$ & OR, $(95 \% \mathrm{CI})$ \\
\hline \multicolumn{6}{|c|}{ Glycemic Index (median, range) $^{b}$} \\
\hline Q1: 46 (27-49) & 374 & 67 & 1.00 & 69 & 1.00 \\
\hline Q2: 50 (49-51) & 374 & 64 & $0.89(0.59-1.36)$ & 74 & $0.98(0.67-1.45)$ \\
\hline Q3: 53 (51-54) & 368 & 80 & $0.91(0.61-1.37)$ & 94 & $1.07(0.73-1.56)$ \\
\hline Q4: 57 (54-71) & 374 & 77 & $0.82(0.54-1.26)$ & 81 & $0.78(0.52-1.18)$ \\
\hline P-trend ${ }^{c}$ & & & 0.42 & & 0.33 \\
\hline Per 10 unit/day increment & & & $0.81(0.58-1.12)$ & & $0.83(0.61-1.13)$ \\
\hline \multicolumn{6}{|l|}{ Glycemic Load (median, range) $^{\mathrm{b}}$} \\
\hline Q1: 95 (21-105) & 373 & 74 & 1.00 & 82 & 1.00 \\
\hline Q2: $113(105-120)$ & 375 & 77 & $1.03(0.69-1.54)$ & 100 & $1.15(0.80-1.65)$ \\
\hline Q3: 126 (120-135) & 371 & 77 & $0.88(0.59-1.31)$ & 68 & $0.75(0.51-1.11)$ \\
\hline Q4: 146 (135-259) & 371 & 60 & $0.73(0.48-1.13)$ & 68 & $0.72(0.49-1.08)$ \\
\hline P-trend ${ }^{c}$ & & & 0.12 & & 0.03 \\
\hline Per 50 unit/day increment & & & $0.83(0.60-1.16)$ & & $0.78(0.57-1.07)$ \\
\hline \multicolumn{6}{|c|}{ Carbohydrate (g/day) (median, range) } \\
\hline Q1: 196 (94-212) & 372 & 79 & 1.00 & 87 & 1.00 \\
\hline Q2: 224 (212-235) & 375 & 82 & $1.14(0.77-1.68)$ & 97 & $1.21(0.84-1.73)$ \\
\hline Q3: $245(235-256)$ & 374 & 69 & $0.90(0.59-1.38)$ & 76 & $0.95(0.64-1.40)$ \\
\hline Q4: $273(256-438)$ & 369 & 58 & $0.79(0.49-1.25)$ & 58 & $0.75(0.48-1.16)$ \\
\hline P-trend ${ }^{c}$ & & & 0.21 & & 0.13 \\
\hline Per 50 g/day increment & & & $0.94(0.74-1.21)$ & & $0.87(0.69-1.09)$ \\
\hline \multicolumn{6}{|l|}{ Starch (g/day) (median, range) ${ }^{b}$} \\
\hline Q1: 74 (31-85) & 372 & 85 & 1.00 & 90 & 1.00 \\
\hline Q2: 93 (85-100) & 374 & 73 & $1.00(0.68-1.49)$ & 79 & $0.90(0.62-1.31)$ \\
\hline Q3: 107 (100-116) & 372 & 66 & $0.89(0.59-1.33)$ & 84 & $0.99(0.69-1.43)$ \\
\hline Q4: $128(116-249)$ & 372 & 64 & $0.80(0.53-1.21)$ & 65 & $0.71(0.48-1.06)$ \\
\hline P-trend ${ }^{c}$ & & & 0.25 & & 0.17 \\
\hline Per 50 g/day increment & & & $0.85(0.63-1.16)$ & & $0.86(0.64-1.14)$ \\
\hline \multicolumn{6}{|c|}{ Total sugars (g/day) (median, range) ${ }^{b}$} \\
\hline Q1: 90 (25-106) & 374 & 74 & 1.00 & 97 & 1.00 \\
\hline Q2: 116 (106-126) & 371 & 71 & $1.10(0.73-1.67)$ & 84 & $1.01(0.69-1.46)$ \\
\hline Q3: 136 (126-148) & 374 & 68 & $1.18(0.76-1.84)$ & 67 & $0.90(0.60-1.34)$ \\
\hline Q4: 168 (148-395) & 371 & 75 & $1.22(0.77-1.92)$ & 70 & $0.88(0.58-1.35)$ \\
\hline P-trend ${ }^{c}$ & & & 0.38 & & 0.47 \\
\hline Per 50 g/day increment & & & $1.08(0.85-1.36)$ & & $1.01(0.81-1.27)$ \\
\hline \multicolumn{6}{|l|}{ Fiber (g/day) (median, range) ${ }^{b}$} \\
\hline Q1: $21(7-25)$ & 371 & 106 & 1.00 & 122 & 1.00 \\
\hline Q2: $28(25-30)$ & 374 & 77 & $0.78(0.54-1.14)$ & 99 & $0.91(0.65-1.27)$ \\
\hline Q3: 33 (30-36) & 372 & 58 & $0.63(0.41-0.95)$ & 68 & $0.63(0.43-0.91)$ \\
\hline
\end{tabular}


Table 2 Odds ratios and 95\% confidence intervals for esophageal adenocarcinomas and gastro-esophageal junction adenocarcinomas according to glycemic index, glycemic load, and dietary carbohydrate intakes, Australia 2002-2005 (Continued)

\begin{tabular}{|c|c|c|c|c|c|}
\hline Q4: 41 (36-74) & 373 & 47 & $0.49(0.31-0.77)$ & 36 & $0.34(0.21-0.54)$ \\
\hline P-trend ${ }^{c}$ & & & 0.001 & & $<.0001$ \\
\hline Per 10 g/day increment & & & $0.72(0.59-0.87)$ & & $0.63(0.53-0.76)$ \\
\hline \multicolumn{6}{|c|}{$\begin{array}{l}\text { a Multivariable Model: adjusted for age, sex, education, BMI, smoking (pack years), physical activity, lifetime mean alcohol intake, acid reflux symptoms in last } \\
10 \text { years, non-steroidal anti-inflammatory drug (NSAID) use, presence of diabetes, total fruit intake (except for fiber intake), red meat, processed meat, and } \\
\text { total energy. } \\
\text { bSex-specific quartile cut-off points are: glycemic index } 47,50,53 \text { for women and } 49,52,55 \text { for men; glycemic load } 102,117,132 \text { for women and } 106,121,136 \text { for } \\
\text { men; carbohydrate } 215,237,259 \text { for women and } 211,234,255 \text { for men; starch } 85,100,114 \text { for women and } 85,100,117 \text { for men; sugar } 115,132,151 \text { for women } \\
\text { and } 102,123,145 \text { for men; fiber } 27,32,39 \text { for women and } 24,29,35 \text { for men. } \\
\text { c Likelihood ratio test for trend across dietary variables quartiles by using an ordinal variable coded as the median value of the quartile. }\end{array}$} \\
\hline
\end{tabular}

with lowest quartile (both $\mathrm{p}$ trend $<0.0006$ ). Mean fiber intake was strongly and inversely associated with risk of EAC, EGJAC, and ESCC (all p trend <0.001). Specifically, the cancer risk for each subtype was reduced between $28 \%-37 \%$ per $10 \mathrm{~g} /$ day increment of fiber intake (OR, 95\%CI: EAC 0.72, 0.59-0.87; EGJAC 0.63, 0.53-0.76; ESCC 0.64, 0.52-0.79).

To assess potential effect modification of the GI/GLesophageal cancer association by selected covariates, interaction terms for each glycemic/carbohydrate factor with sex, BMI, smoking status or alcohol consumption were tested. None of the tested interactions were statistically significant with few exceptions. We observed that the association between GL and ESCC was modified by sex $\left(\mathrm{p}_{\text {interaction }}=0.02\right)$ presented in Figure 1 . The inverse risk pattern was confined to men only (OR, $95 \% \mathrm{CI}$; quartile 2 : $0.48,0.28-0.80$; quartile $3: 0.34,0.19-0.63$; quartile $4: 0.42$, 0.24-0.74), while no clear association became apparent among women (OR, 95\%CI; quartile 2: 1.13, 0.53-2.38; quartile 3: 1.61, 0.77-3.39; quartile 4: 1.07, 0.50-2.32) as shown in sex-specific Additional file 2: Table S2 and Additional file 3: Table S3. Similar to GL, the carbohydrates and starch associations differed by sex (total carbohydrates: $\mathrm{p}$ interaction $=0.02$; starch: $\mathrm{p}$ interaction $=0.03$ ). The decreased risk of ESCC was accentuated in men only (Additional file 2: Table S2 and Additional file 3: Table S3). Further, we examined the potential effect modification of the GI/GL/carbohydrate component-esophageal cancer association by red meat intake and saturated fat intake (data not shown). There was no evidence that these dietary factors modified the association between GI or GL and any subtype. For ESCC only, in stratified analysis, the inverse total carbohydrates association remained only among those with high red meat intake (median split: $>91 \mathrm{~g} / \mathrm{d}, \mathrm{p}$ trend $=0.0005$ ), while the inverse fiber association was confined to those with low fat intake (median split: $<26.5 \mathrm{~g} / \mathrm{d}, \mathrm{p}_{\text {trend }}<0.0001$ ).

\section{Discussion}

In this large case-control study of Australian men and women, GI was unrelated to risk of all histologic types of esophageal cancer. GL was not associated with risk of EAC and EGJAC, but was inversely associated with risk of ESCC (30\% risk reduction per 10 unit/d increment). This dose-dependent association was independent of other established risk factors, including smoking status, alcohol consumption, BMI and selected dietary factors. Sexstratified analysis indicated that this association was confined to men only. Similar to GL, higher intakes of total carbohydrates and starch were significantly related to lowered risk of ESCC. Total dietary fiber intake was inversely and strongly associated with all three tumor types independent of sex (all $\mathrm{p}_{\text {trend }} \leq 0.001$ ).

While published data on colorectal cancer suggest a small to moderate increased risk with higher GI or GL $[6,13,20]$, findings derived from the few published reports on esophageal cancer are not clear and reported associations are of low magnitude. Results based on the prospective National Institutes of Health $(\mathrm{NIH})$-AARP Diet and Health Study [20] indicate that among men, higher GI, but not GL, was associated with increased risk of esophageal cancers (adenocarcinoma and squamous cell carcinoma combined, 425 cases). Interestingly, in stratified analyses, this association remained significant only among smokers (former/current), men with a high BMI, or high saturated fat intake. The FINBAR case-control study [18] including 224 EAC cases (84\% men), showed a $42 \%$ increased risk per 10 unit higher GI intake for this tumor type, and appeared to be stronger (but not significantly) in centrally overweight individuals. An earlier hospital-based case-control study [19] including 304 ESCC cases (90\% men), suggested borderline significant direct associations between GI (OR (95\%CI) 1.1, 0.9-1.5, per 10-unit/d increment) or GL (1.2, 1.0-1.5, per 100-unit/d increment) and ESCC risk.

Our observations made in the present study differ from previous evidence in that glycemic indicators seem to have a higher impact on risk of ESCC than on either type of adenocarcinoma of the esophagus, and rather GL, not GI, had a relevant effect on cancer risk. The latter finding supports the suggestion by $\mathrm{Hu}$ et al. [35] that GL is a more physiologically relevant measure than GI 
Table 3 Odds ratios and $95 \%$ confidence intervals for esophageal squamous cell carcinoma according to glycemic index, glycemic load, and dietary carbohydrate intakes, Australia 2002-2005

\begin{tabular}{|c|c|c|c|}
\hline & \multirow{3}{*}{$\begin{array}{l}\text { Controls } \\
\mathrm{N}=1490\end{array}$} & \multirow{2}{*}{\multicolumn{2}{|c|}{$\begin{array}{c}\text { ESCC } \\
\text { Multivariable model }^{a}\end{array}$}} \\
\hline & & & \\
\hline & & $\mathrm{N}=227$ & OR, $(95 \% \mathrm{Cl})$ \\
\hline \multicolumn{4}{|c|}{ Glycemic Index (median, range) } \\
\hline Q1: 46 (27-49) & 374 & 60 & 1.00 \\
\hline Q2: 50 (49-51) & 374 & 39 & $0.66(0.41-1.05)$ \\
\hline Q3: 53 (51-54) & 368 & 58 & $1.01(0.66-1.56)$ \\
\hline Q4: 57 (54-71) & 374 & 70 & $0.73(0.46-1.14)$ \\
\hline P-trend ${ }^{c}$ & & & 0.44 \\
\hline Per 10 unit/day increment & & & $0.89(0.66-1.21)$ \\
\hline \multicolumn{4}{|l|}{ Glycemic Load (median, range) $^{\mathrm{b}}$} \\
\hline Q1: 95 (21-105) & 373 & 85 & 1.00 \\
\hline Q2: $113(105-120)$ & 375 & 52 & $0.61(0.40-0.92)$ \\
\hline Q3: 126 (120-135) & 371 & 48 & $0.67(0.44-1.02)$ \\
\hline Q4: 146 (135-259) & 371 & 42 & $0.52(0.33-0.82)$ \\
\hline P-trend ${ }^{c}$ & & & 0.006 \\
\hline Per 50 unit/day increment & & & $0.70(0.50-0.97)$ \\
\hline \multicolumn{4}{|c|}{ Carbohydrate (g/day) (median, range) } \\
\hline Q1: 196 (94-212) & 372 & 98 & 1.00 \\
\hline Q2: 224 (212-235) & 375 & 58 & $0.81(0.54-1.21)$ \\
\hline Q3: 245 (235-256) & 374 & 35 & $0.55(0.35-0.87)$ \\
\hline Q4: 273 (256-438) & 369 & 36 & $0.46(0.28-0.75)$ \\
\hline P-trend ${ }^{c}$ & & & 0.0005 \\
\hline Per 50 g/day increment & & & $0.72(0.56-0.92)$ \\
\hline \multicolumn{4}{|l|}{ Starch (g/day) (median, range) ${ }^{b}$} \\
\hline Q1: 74 (31-85) & 372 & 91 & 1.00 \\
\hline Q2: 93 (85-100) & 374 & 49 & $0.55(0.36-0.84)$ \\
\hline Q3: 107 (100-116) & 372 & 44 & $0.52(0.34-0.80)$ \\
\hline Q4: $128(116-249)$ & 372 & 43 & $0.46(0.29-0.71)$ \\
\hline P-trend ${ }^{c}$ & & & 0.0003 \\
\hline Per 50 g/day increment & & & $0.60(0.43-0.82)$ \\
\hline \multicolumn{4}{|c|}{ Total sugars (g/day) (median, range) ${ }^{b}$} \\
\hline Q1: 90 (25-106) & 374 & 97 & 1.00 \\
\hline Q2: 116 (106-126) & 371 & 35 & $0.54(0.34-0.85)$ \\
\hline Q3: 136 (126-148) & 374 & 47 & $0.79(0.51-1.23)$ \\
\hline Q4: 168 (148-395) & 371 & 48 & $0.83(0.53-1.32)$ \\
\hline P-trend ${ }^{c}$ & & & 0.59 \\
\hline Per 50 g/day increment & & & $0.86(0.68-1.09)$ \\
\hline \multicolumn{4}{|l|}{ Fiber (g/day) (median, range) ${ }^{b}$} \\
\hline Q1: 21 (7-25) & 371 & 93 & 1.0 \\
\hline Q2: 28 (25-30) & 374 & 53 & $0.64(0.43-0.97)$ \\
\hline Q3: 33 (30-36) & 372 & 45 & $0.45(0.29-0.71)$ \\
\hline
\end{tabular}


Table 3 Odds ratios and $95 \%$ confidence intervals for esophageal squamous cell carcinoma according to glycemic index, glycemic load, and dietary carbohydrate intakes, Australia 2002-2005 (Continued)

\begin{tabular}{|c|c|c|c|}
\hline Q4: 41 (36-74) & 373 & 36 & $0.38(0.23-0.63)$ \\
\hline P-trend ${ }^{c}$ & & & $<.0001$ \\
\hline Per $10 \mathrm{~g} /$ day increment & & & $0.64(0.52-0.79)$ \\
\hline
\end{tabular}

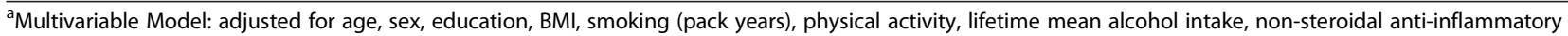
drug (NSAID) use, total fruit intake (except for fiber intake), red meat, processed meat, and total energy.

${ }^{b}$ Sex-specific quartile cut-off points are: glycemic index 47, 50, 53 for women and 49, 52, 55 for men; glycemic load 102, 117, 132 for women and 106, 121, 136 for men; carbohydrate 215, 237, 259 for women and 211, 234, 255 for men; starch 85, 100, 114 for women and 85, 100, 117 for men; sugar 115, 132, 151 for women and 102, 123, 145 for men; fiber 27, 32, 39 for women and 24, 29, 35 for men.

cLikelihood ratio test for trend across dietary variables quartiles by using an ordinal variable coded as the median value of the quartile.

in terms of associated risk with chronic disease. Further, because of the narrow distribution of GI values (27-71, median 52) in this study population which centered around the middle of the theoretical range for GI (0-100), we may have not been able to detect significant effects of different levels of GI. This issue has also been raised by other investigators [20,36]. Moreover, in contrast to the NIH-AARP Diet and Health Study [20] we did not observe any effect modification by smoking status (ever/ never), BMI $(<25>)$, or saturated fat intake (median split) on the GI/GL-esophageal cancer association (data not shown).

We have no straightforward explanation for the observed moderate inverse association between GL and ESCC risk which was observed only among men after stratification by sex. It has been suggested that the direction and magnitude of glycemic indicators-cancer associations may be explained by the way in which high GI

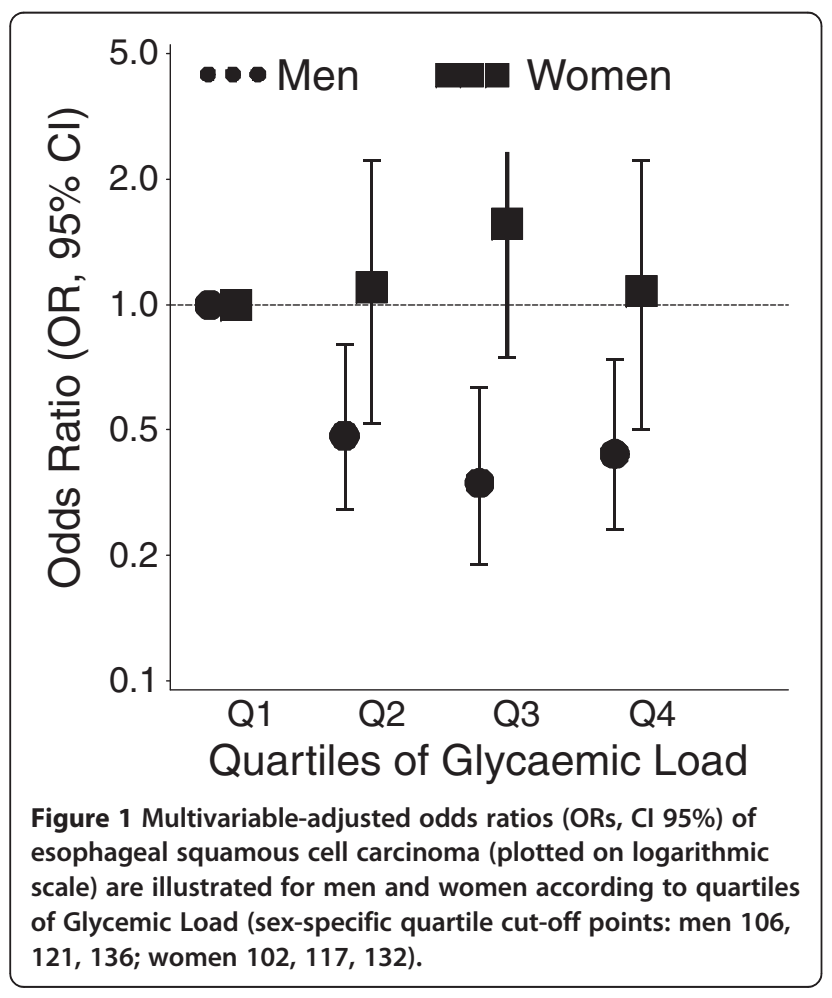

or high GL track with other dietary and lifestyle factors related to cancer development [20]. For instance, in the NIH-AARP cohort, high GL diets were inversely related to total cancer only among adults with low BMI [20]. This is compatible with our finding of the inverse GLesophageal cancer association among ESCC cases only, who on average have lower BMI than their counterparts diagnosed with EAC or EGJAC as documented in this and our previous studies [23,37]. Considering each tumor type separately, however, the GI/GL-esophageal cancer association was consistent across all BMI levels; hence BMI did not modify the relation between GI or GL and any of the histologic types.

Higher fiber intake was associated with reduced risks of all three tumor types in our investigation (28-37\% risk reduction per 10-unit/d increment). This is in accordance with other population-based case-control studies demonstrating an inverse association between dietary fiber and risk of EAC [18,38-42], EGJAC [40-42], and ESCC [40]. Based on our findings, no obvious heterogeneity of the association between fiber and adenocarcinoma and squamous cell carcinoma of the esophagus became apparent, which is similar to one previous report [40], but contrasts with another [41]. In the latter study total dietary fiber intake was significantly related to gastric cardia adenocarcinoma only. A recent meta-analysis on dietary fiber and esophageal cancer risk, including a total of 10 populationbased or hospital-based case-control studies, also indicates a more consistent inverse association for EAC than for ESCC [43]. When exploring potential effect modification by selected dietary factors, we observed that the inverse fiber-ESCC association was confined to those individuals with lower fat intake.

Fiber has a potential role in cancer prevention by beneficially influencing blood glucose control, lipid profiles, and body weight [44-46]. Although the protective mechanism of fiber is not well understood, it may act by mechanical removal of carcinogens from food items that pass through the digestive tract and/or removal of damaged cells from the epithelial surface, by lowering plasma levels of biomarkers of systemic inflammation, and by reducing risk of hiatus hernia and gastro-esophageal reflux symptoms, or by mediating the glycemic response 
as summarized by others $[12,18,40,43]$. However, similar to overall carbohydrate intake, high fiber intake may be a proxy for a diet rich in other bioactive constituents (e.g. micronutrients) that are protective against cancer, including esophageal malignancies.

Some limitations warrant consideration when interpreting results of our study. A potential shortcoming was the low participation rate among controls, which increases the likelihood that our control sample was not representative of the population from which the cases arose. To assess the magnitude of possible bias, we compared smoking and obesity prevalence in the control group with that reported in the 2004 Australian National Health Survey (NHS) [47]. The prevalence of ever-smoking and the distribution of BMI in our study were similar to those in the NHS, and using the NHS distributions to impute BMI values for nonparticipating controls had minimal effect on risk estimates [48]. Dietary measurement errors may have occurred in our dietary assessment, including nondifferential misclassification of exposure, and dietary recall bias related to cancer status, BMI and possibly other relevant exposures all of which would attenuate effect estimates $[49,50]$. It is likely that systematic error may be present due to misreporting of energy- and macronutrient intake by BMI status [51] specifically selective underreporting by overweight women [52]. Other limitations include the possibility of residual confounding from smoking, alcohol consumption, and unmeasured variables. We have not validated the assessment of GI or GL against an objective standard or using a different dietary method. However, average GI and GL intake values of female and male participants in our study are compatible with dietary data from other Australian studies assessed by FFQ $[53,54]$ or diet history interview [55].

Major strengths of our population-based study include its large sample size, the examination of three different but related esophageal cancer endpoints, a high caseresponse rate, and the comprehensive control of other risk factors.

\section{Conclusions}

In conclusion, this case-control study in Australian adults suggests a reduced risk of esophageal SCC with higher GL level, most notably among men, but provides no evidence for the role of a high GI diet in the development of adenocarcinomas or squamous cell carcinomas of the esophagus. Increased total fiber intake appeared to be comparably protective for all histological types. This finding is in accordance with previous evidence from case-control studies on esophageal cancers. Given the limited number of epidemiological studies on glycemic indicators and risk of adenocarcinomas and squamous cell carcinoma of the esophagus, it remains to be shown whether GI and/or GL are meaningful predictors of these malignancies.

\section{Additional files}

Additional file 1: Table S1. The Australian Cancer Study, names of the ethics committees from all institutions that approved this study.

Additional file 2: Table S2. Odds ratios and 95\% confidence intervals for esophageal squamous cell carcinoma according to glycemic index, glycemic load, and dietary carbohydrate intakes in men, Australia 2002-2005.

Additional file 3: Table S3. Odds ratios and 95\% confidence intervals for esophageal squamous cell carcinoma according to glycemic index, glycemic load, and dietary carbohydrate intakes in women, Australia 2002-2005.

\section{Competing interests}

The authors declare that they have no competing interests.

\section{Authors' contributions}

PHL conceived the analysis plan and design, provided technical assistance to statistical analysis, interpreted the data and wrote the manuscript. TII carried out the statistical analysis and participated in the design of the study, with assistance from CMN. DCW and PMW obtained funding, managed and conducted the Australian Cancer Study. All authors made intellectual contributions to and read and approved the final manuscript.

\section{Acknowledgements}

We thank Maria Celia Hughes for her valuable advice in dietary methodology issues and Shahram Sadeghi, MD, PhD and Harish Babu, MD for their assistance with pathology abstractions and all staff of the Australian Cancer Study: Esophageal Cancer.

This work was supported by program grants from the National Health and Medical Research Council of Australia (grant numbers 199600, 552429, APP1043134 to PMW); Cancer Council (grant number 496680) and Australian Research Council (FT0990987 to DCW)

Received: 15 March 2014 Accepted: 13 November 2014

Published: 24 November 2014

\section{References}

1. Ferlay J, Parkin DM, Steliarova-Foucher E: Estimates of cancer incidence and mortality in Europe in 2008. Eur J Cancer 2010, 46(4):765-781.

2. Nyren O, Adami HO: Esophageal Cancer. In Textbook of Cancer Epidemiology. 2nd edition. Edited by Adami HO, Hunter D, Trichopoulos D. Oxford, UK: Oxford University Press; 2008:196-238.

3. Calle EE, Kaaks R: Overweight, obesity and cancer: epidemiological evidence and proposed mechanisms. Nat Rev Cancer 2004, 4(8):579-591.

4. Kaaks R, Lukanova A: Energy balance and cancer: the role of insulin and insulin-like growth factor-I. Proc Nutr Soc 2001, 60(1):91-106.

5. Augustin LS, Franceschi S, Jenkins DJ, Kendall CW, La Vecchia C: Glycemic index in chronic disease: a review. Eur J Clin Nutr 2002, 56(11):1049-1071.

6. Gnagnarella P, Gandini S, La Vecchia C, Maisonneuve P: Glycemic index, glycemic load, and cancer risk: a meta-analysis. Am J Clin Nutr 2008, 87(6):1793-1801.

7. Thompson CL, Khiani V, Chak A, Berger NA, Li L: Carbohydrate consumption and esophageal cancer:an ecological assessment. Am J Gastroenterol 2008, 103(3):555-561.

8. Jenkins DJ, Kendall CW, Augustin LS, Franceschi S, Hamidi M, Marchie A, Jenkins $\mathrm{AL}$, Axelsen M: Glycemic index: overview of implications in health and disease. Am J Clin Nutr 2002, 76(1):266S-273S.

9. Jenkins DJ, Wolever TM, Taylor RH, Barker H, Fielden H, Baldwin JM, Bowling AC, Newman HC, Jenkins AL, Goff DV: Glycemic index of foods: a physiological basis for carbohydrate exchange. Am J Clin Nutr 1981, 34(3):362-366.

10. Pi-Sunyer FX: Glycemic index and disease. Am J Clin Nutr 2002, 76(1):290S-298S

11. Foster-Powell K, Holt SH, Brand-Miller JC: International table of glycemic index and glycemic load values: 2002. Am J Clin Nutr 2002, 76(1):5-56

12. Kubo A, Corley DA, Jensen CD, Kaur R: Dietary factors and the risks of oesophageal adenocarcinoma and Barrett's oesophagus. Nutr Res Rev 2010, 23(2):230-246. 
13. Mulholland HG, Murray LJ, Cardwell CR, Cantwell MM: Glycemic index, glycemic load, and risk of digestive tract neoplasms: a systematic review and meta-analysis. Am J Clin Nutr 2009, 89(2):568-576.

14. Neale RE, Doecke JD, Pandeya N, Sadeghi S, Green AC, Webb PM, Whiteman DC: Does type 2 diabetes influence the risk of oesophageal adenocarcinoma? Br J Cancer 2009, 100(5):795-798.

15. Biddinger SB, Ludwig DS: The insulin-like growth factor axis: a potential link between glycemic index and cancer. Am J Clin Nutr 2005, 82(2):277-278

16. Brand-Miller JC, Liu V, Petocz P, Baxter RC: The glycemic index of foods influences postprandial insulin-like growth factor-binding protein responses in lean young subjects. Am J Clin Nutr 2005, 82(2):350-354.

17. Key TJ, Spencer EA: Carbohydrates and cancer: an overview of the epidemiological evidence. Eur J Clin Nutr 2007, 61(Suppl 1):S112-121.

18. Mulholland HG, Cantwell MM, Anderson LA, Johnston BT, Watson RG, Murphy SJ, Ferguson HR, McGuigan J, Reynolds JV, Comber H, Murray L: Glycemic index, carbohydrate and fiber intakes and risk of reflux esophagitis, Barrett's esophagus, and esophageal adenocarcinoma. Cancer Causes Control 2009, 20(3):279-288.

19. Augustin LS, Gallus S, Franceschi S, Negri E, Jenkins DJ, Kendall CW, Dal Maso L, Talamini R, La Vecchia C: Glycemic index and load and risk of upper aero-digestive tract neoplasms (Italy). Cancer Causes Control 2003, 14(7):657-662.

20. George SM, Mayne ST, Leitzmann MF, Park Y, Schatzkin A, Flood A, Hollenbeck A, Subar AF: Dietary glycemic index, glycemic load, and risk of cancer: a prospective cohort study. Am J Epidemiol 2009, 169(4):462-472.

21. Tasevska N, Jiao L, Cross AJ, Kipnis V, Subar AF, Hollenbeck A, Schatzkin A, Potischman N: Sugars in diet and risk of cancer in the NIH-AARP Diet and Health Study. Int I Cancer 2012, 130(1):159-169.

22. Spechler SJ: Barrett's esophagus: an overrated cancer risk factor. Gastroenterology 2000, 119(2):587-589.

23. Whiteman DC, Sadeghi S, Pandeya N, Smithers BM, Gotley DC, Bain CJ, Webb PM, Green AC: Combined effects of obesity, acid reflux and smoking on the risk of adenocarcinomas of the oesophagus. Gut 2008, 57(2):173-180

24. Merritt MA, Green AC, Nagle CM, Webb PM: Talcum powder, chronic pelvic inflammation and NSAIDs in relation to risk of epithelial ovarian cancer. Int I Cancer 2008, 122(1):170-176.

25. Willett WC, Sampson L, Stampfer MJ, Rosner B, Bain C, Witschi J, Hennekens $\mathrm{CH}$, Speizer FE: Reproducibility and validity of a semiquantitative food frequency questionnaire. Am J Epidemiol 1985, 122(1):51-65.

26. Ibiebele TI, Parekh S, Mallitt KA, Hughes MC, O'Rourke PK, Webb PM: Reproducibility of food and nutrient intake estimates using a semi-quantitative FFQ in Australian adults. Public Health Nutr 2009, 12(12):2359-2365.

27. McNaughton SA, Marks GC, Gaffney P, Williams G, Green A: Validation of a food-frequency questionnaire assessment of carotenoid and vitamin $E$ intake using weighed food records and plasma biomarkers: the method of triads model. Eur J Clin Nutr 2005, 59(2):211-218.

28. Marks GC, Hughes MC, van der Pols JC: Relative validity of food intake estimates using a food frequency questionnaire is associated with sex, age, and other personal characteristics. J Nutr 2006, 136(2):459-465.

29. Marks GC, Hughes MC, van der Pols JC: The effect of personal characteristics on the validity of nutrient intake estimates using a food-frequency questionnaire. Public Health Nutr 2006, 9(3):394-402.

30. Food Standards Australia New Zealand (FSANZ): NUTTAB 2006: Australian Food Composition Tables. In Food Standards Australia New Zealand. Canberra: FSANZ; 2007

31. Atkinson FS, Foster-Powell K, Brand-Miller JC: International tables of glycemic index and glycemic load values: 2008. Diabetes Care 2008, 31(12):2281-2283.

32. Liu S, Willett WC, Stampfer MJ, Hu FB, Franz M, Sampson L, Hennekens CH, Manson JE: A prospective study of dietary glycemic load, carbohydrate intake, and risk of coronary heart disease in US women. Am J Clin Nutr 2000, 71(6):1455-1461.

33. World Health Organization (WHO): Obesity: Preventing And Managing The Global Epidemic: Report of a WHO Consultation. In WHO Technical Report Series (894). Geneva: World Health Organization; 2000.

34. Olsen CM, Bain CJ, Jordan SJ, Nagle CM, Green AC, Whiteman DC, Webb PM: Recreational physical activity and epithelial ovarian cancer: a case- control study, systematic review, and meta-analysis. Cancer Epidemiol Biomarkers Prev 2007, 16(11):2321-2330.

35. Hu FB, van Dam RM, Liu S: Diet and risk of Type II diabetes: the role of types of fat and carbohydrate. Diabetologia 2001, 44(7):805-817.

36. Flood A, Peters U, Jenkins DJ, Chatterjee N, Subar AF, Church TR, Bresalier R, Weissfeld JL, Hayes RB, Schatzkin A: Carbohydrate, glycemic index, and glycemic load and colorectal adenomas in the Prostate, Lung, Colorectal, and Ovarian Screening Study. Am J Clin Nutr 2006, 84(5):1184-1192.

37. Lahmann PH, Pandeya N, Webb PM, Green AC, Whiteman DC: Body mass index, long-term weight change, and esophageal squamous cell carcinoma: Is the inverse association modified by smoking status? Cancer 2012, 118(7):1901-9.

38. Brown LM, Swanson CA, Gridley G, Swanson GM, Schoenberg JB, Greenberg RS, Silverman DT, Pottern LM, Hayes RB, Schwartz AG, Liff JM, Fraumeni JF $\mathrm{Jr}$, Hoover RN: Adenocarcinoma of the esophagus: role of obesity and diet. J Natl Cancer Inst 1995, 87(2):104-109.

39. Chen H, Tucker KL, Graubard BI, Heineman EF, Markin RS, Potischman NA, Russell RM, Weisenburger DD, Ward MH: Nutrient intakes and adenocarcinoma of the esophagus and distal stomach. Nutr Cancer 2002, 42(1):33-40.

40. Mayne ST, Risch HA, Dubrow R, Chow WH, Gammon MD, Vaughan TL, Farrow DC, Schoenberg JB, Stanford JL, Ahsan H, West AB, Rotterdam H, Blot WJ, Fraumeni JF Jr: Nutrient intake and risk of subtypes of esophageal and gastric cancer. Cancer Epidemiol Biomarkers Prev 2001, 10(10):1055-1062

41. Terry P, Lagergren J, Ye W, Wolk A, Nyren O: Inverse association between intake of cereal fiber and risk of gastric cardia cancer. Gastroenterology 2001, 120(2):387-391.

42. Wu AH, Tseng CC, Hankin J, Bernstein L: Fiber intake and risk of adenocarcinomas of the esophagus and stomach. Cancer Causes Control 2007, 18(7):713-722.

43. Coleman HG, Murray LJ, Hicks B, Bhat SK, Kubo A, Corley DA, Cardwell CR, Cantwell MM: Dietary fiber and the risk of precancerous lesions and cancer of the esophagus: a systematic review and meta-analysis. Nutr Rev 2013, 71(7):474-482.

44. Babio N, Balanza R, Basulto J, Bullo M, Salas-Salvado J: Dietary fibre: influence on body weight, glycemic control and plasma cholesterol profile. Nutr Hosp 2010, 25(3):327-340.

45. Slavin JL: Position of the American Dietetic Association: health implications of dietary fiber. J Am Diet Assoc 2008, 108(10):1716-1731.

46. Wanders AJ, van den Borne JJ, de Graaf C, Hulshof T, Jonathan MC, Kristensen M, Mars M, Schols HA, Feskens EJ: Effects of dietary fibre on subjective appetite, energy intake and body weight: a systematic review of randomized controlled trials. Obes Rev 2011, 12(9):724-739.

47. Australian Bureau of Statistics (ABoS): National Health Survey, 2004-05. Canberra: ABS; 2006

48. Pandeya N, Williams GM, Green AC, Webb PM, Whiteman DC: Do low control response rates always affect the findings? Assessments of smoking and obesity in two Australian case-control studies of cancer. Aust N Z J Public Health 2009, 33(4):312-319.

49. Bingham SA, Luben $R$, Welch A, Wareham N, Khaw KT, Day N: Are imprecise methods obscuring a relation between fat and breast cancer? Lancet 2003, 362(9379):212-214.

50. Kipnis V, Midthune D, Freedman L, Bingham S, Day NE, Riboli E, Ferrari $P$, Carroll RJ: Bias in dietary-report instruments and its implications for nutritional epidemiology. Public Health Nutr 2002, 5(6A):915-923.

51. Subar AF, Kipnis $V$, Troiano RP, Midthune D, Schoeller DA, Bingham S, Sharbaugh CO, Trabulsi J, Runswick S, Ballard-Barbash R, Sunshine J, Schatzkin A: Using intake biomarkers to evaluate the extent of dietary misreporting in a large sample of adults: the OPEN study. Am J Epidemiol 2003, 158(1):1-13.

52. Poppitt SD, Swann D, Black AE, Prentice AM: Assessment of selective under-reporting of food intake by both obese and non-obese women in a metabolic facility. Int J Obes Relat Metab Disord 1998, 22(4):303-311.

53. Barclay AW, Brand-Miller JC, Mitchell P: Macronutrient intake, glycaemic index and glycaemic load of older Australian subjects with and without diabetes: baseline data from the Blue Mountains Eye study. Br J Nutr 2006, 96(1):117-123. 
54. Giles GG, Simpson JA, English DR, Hodge AM, Gertig DM, Macinnis RJ, Hopper JL: Dietary carbohydrate, fibre, glycaemic index, glycaemic load and the risk of postmenopausal breast cancer. Int I Cancer 2006, 118(7):1843-1847.

55. O'Sullivan TA, Bremner AP, O'Neill S, Lyons-Wall P: Glycaemic load is associated with insulin resistance in older Australian women. Eur I Clin Nutr 2010, 64(1):80-87.

doi:10.1186/1471-2407-14-877

Cite this article as: Lahmann et al:: A case-control study of glycemic

index, glycemic load and dietary fiber intake and risk of adenocarcinomas

and squamous cell carcinomas of the esophagus: the Australian Cancer

Study. BMC Cancer 2014 14:877.

\section{Submit your next manuscript to BioMed Central and take full advantage of:}

- Convenient online submission

- Thorough peer review

- No space constraints or color figure charges

- Immediate publication on acceptance

- Inclusion in PubMed, CAS, Scopus and Google Scholar

- Research which is freely available for redistribution 